\title{
Suppression of hysteresis in absorption of hydrogen by a Pd-Au alloy
}

\author{
Mikhail Mamatkulov (1) ${ }^{1}$ and Vladimir P. Zhdanov (1) ${ }^{1,2}$ \\ ${ }^{1}$ Boreskov Institute of Catalysis, Russian Academy of Sciences, Novosibirsk, Russia \\ ${ }^{2}$ Department of Physics, Chalmers University of Technology, Göteborg, Sweden
}

(Received 4 September 2019; accepted 23 March 2020; published 23 April 2020)

\begin{abstract}
Hydrogen absorption by Pd exhibits hysteresis loops (provided the temperature is not too high) and represents one of the classical examples of first-order phase transitions in metals. Experiments indicate that addition of even a small amount of $\mathrm{Au}$ is able to suppress hysteresis. From this perspective, we analyze the energetics of hydrogen in a Pd-Au alloy by using extensive density-functional-theory (DFT) calculations. The dependence of the hydrogen binding energy on the number $(n)$ of $\mathrm{Au}$ atoms forming an adsorption site is found to be appreciably nonlinear. With the DFT input for statistical calculations, we reproduce special features of the hydrogen absorption isotherms and explain the rapid decrease of the corresponding critical temperature with increasing Au fraction. The key factor here is that the phase transition is related primarily to absorption in sites formed only by Pd. With increasing Au amount, the fraction of such sites rapidly decreases, the distance between $\mathrm{H}$ atoms located there becomes on average larger, the interaction between them becomes weaker, and accordingly the driving force for the phase transition decreases. It is of interest that all these effects can be illustrated by taking only the configurations with $n \leqslant 2$ into account. This means that in the context under consideration the fine details of the dependence of the hydrogen binding energy on $n$ are in fact not too important.
\end{abstract}

DOI: 10.1103/PhysRevE.101.042130

\section{INTRODUCTION}

Hydrogen absorption by metals is physically of considerable intrinsic interest [1,2] and also important from the perspectives of various applications including hydrogen storage, heat storage, metal hydride batteries, hydrogen sensors, smart windows, and switchable mirrors (see, e.g., [1-4] and references therein). In this area, the H-Pd system is generic. At room temperature, hydrogen is easily absorbed by $\mathrm{Pd}$ and, with increasing $\mathrm{H}_{2}$ pressure, exhibits a first-order transition from a diluted $\alpha$ phase to a dense $\beta$ phase representing a hydride with the $\mathrm{H} / \mathrm{Pd}$ ratio $\simeq 0.66$ [1]. This phase transition is manifested in the observation of a well-developed hysteresis loop in the absorption isotherms at temperatures below the critical one, $T \leqslant T_{\text {c }}$. Experiments performed at $T \geqslant 300 \mathrm{~K}$ indicate that addition of even a small amount of $\mathrm{Au}$ (with fraction $f \leqslant 0.2$ ) makes hydrogen absorption less favorable [5] and appreciably reduces $T_{\mathrm{c}}$ [4,6,7]. Although in general this interesting generic effect was analyzed by using a statistical mean-field model [8], its quantitative interpretation from first principles has not been done, to our knowledge, and is challenging because the $\mathrm{H}$ binding energy is relatively small on the scale of conventional chemical bonds and there is a large number of various combinations of metal atoms forming a binding site. Herein, we address this challenge by combining

Published by the American Physical Society under the terms of the Creative Commons Attribution 4.0 International license. Further distribution of this work must maintain attribution to the author(s) and the published article's title, journal citation, and DOI. Funded by Bibsam. extensive DFT calculations with a statistical model of phase transitions.

The already available related DFT studies are focused on various features of the system under consideration: (i) One of the first questions addressed concerns the type of sites for hydrogen absorption in pure $\mathrm{Pd}$. In agreement with experiment [9], the theory indicates that the octahedral (O) absorption sites are energetically more favorable than the tetrahedral $(\mathrm{T})$ sites at $\mathrm{H} / \mathrm{Pd}$ ratios up to 1 [10-13]. In addition, the theory was used to clarify the specifics of the band structure [12] and phonon dispersion of $\mathrm{PdH}[12,14,15]$, the dynamics of $\mathrm{H}$ diffusion [16], the effect of lattice strain on $\mathrm{H}$ diffusion [11], the energetics of subsurface $\mathrm{H}$ absorption [17,18], and the effect of vacancies on $\mathrm{H}$ absorption $[14,19]$. (ii) For pure $\mathrm{Au}, \mathrm{DFT}$ is in favor of $\mathrm{H}$ absorption on the $\mathrm{T}$ sites, whereas the $\mathrm{H}$ location in the $\mathrm{O}$ sites is predicted to be unstable $[13,19]$. (iii) For a Pd-Au alloy, the theory was used to scrutinize the arrangement of atoms [20-24]. In addition, DFT indicates that hydrogen absorption becomes less favorable with increasing Au content $[25,26]$. Detailed tables with the binding energies and frequencies of vibrations of $\mathrm{H}$ atoms for $\mathrm{H}$ absorption on sites with different arrangements of $\mathrm{Pd}$ and $\mathrm{Au}$ atoms are, however, lacking there, and accordingly the use of the data reported was not straightforward in our context.

Our results are presented in five sections focused on basic aspects of $\mathrm{H}$ absorption in a Pd-Au alloy (Sec. II), DFT calculations of $\mathrm{H}$-absorption energies for various configurations of Pd and Au atoms (Sec. III), validation of the level needed to calculate the probabilities of configurations of $\mathrm{Pd}$ and $\mathrm{Au}$ atoms (Sec. IV), calculations of the absorption isotherms at different $T$ and $f$ and dependence of $T_{\mathrm{c}}$ on $f$ (Sec. V), and conclusions (Sec. VI). 
TABLE I. Calculated energy of the Pd-Au cell without hydrogen.

\begin{tabular}{lc}
\hline \hline Site & Energy $(\mathrm{eV})$ \\
\hline $\mathrm{O}\left(\mathrm{Pd}_{6}\right.$-bulk $)$ & -559.5201 \\
$\mathrm{O}\left(\mathrm{Pd}_{5} \mathrm{Au}_{1}\right)$ & -557.7375 \\
$\mathrm{O}\left(\mathrm{Pd}_{4} \mathrm{Au}_{2}-\mathrm{a}\right)$ & -555.9665 \\
$\mathrm{O}\left(\mathrm{Pd}_{4} \mathrm{Au}_{2}-\mathrm{b}\right)$ & -555.9370 \\
$\mathrm{O}\left(\mathrm{Pd}_{3} \mathrm{Au}_{3}-\mathrm{a}\right)$ & -554.1469 \\
$\mathrm{O}\left(\mathrm{Pd}_{3} \mathrm{Au}_{3}-\mathrm{b}\right)$ & -554.1197 \\
$\mathrm{O}\left(\mathrm{Pd}_{2} \mathrm{Au}_{4}-\mathrm{a}\right)$ & -552.3374 \\
$\mathrm{O}\left(\mathrm{Pd}_{2} \mathrm{Au}_{4}-\mathrm{b}\right)$ & -552.3111 \\
$\mathrm{O}\left(\mathrm{Pd}_{1} \mathrm{Au}_{5}\right)$ & -550.4831 \\
$\mathrm{O}\left(\mathrm{Au}_{6}\right.$-bulk $)$ & -353.4290 \\
\hline \hline
\end{tabular}

\section{BASICS OF H ABSORPTION IN A Pd-Au ALLOY}

The reduction of $T_{\mathrm{c}}$ with increasing $\mathrm{Au}$ amount in a $\mathrm{Pd}-\mathrm{Au}$ alloy was observed in experiments with foils [6] and relatively large nanoparticles (NPs) [4,7] (150-200 nm in diameter) where in the absence of $\mathrm{Au}$ the hysteresis in absorption isotherms is well developed. The kinetics of hydrogen absorption by NPs in general and such NPs in particular can be influenced by adsorption on their surface and depends on the surface structure (see, e.g., [27]). The thermodynamics of absorption (i.e., absorption isotherms) by the NPs under consideration is, however, not sensitive to the surface (this factor is important at much smaller sizes; see, e.g., [28,29]). For this reason, our analysis is focused on hydrogen in the bulk.

In general, the energy of a $\mathrm{H}$ atom in a $\mathrm{Pd}-\mathrm{Au}$ alloy can be represented as

$$
E_{\mathrm{total}}=E_{\mathrm{abs}}(n, i)+\epsilon_{\mathrm{HH}}(\theta)-v_{\circ} \sigma_{i i} / 3,
$$

where $E_{\text {abs }}(n, i)$ is the absorption energy at $\theta \ll 1[\theta$ is the $\mathrm{H}$ uptake per metal atom, $n$ is the number of Au atoms forming a site, and $i$ is the variable specifying various sites at a given $n$ (in Table I, $i$ can be identified with "a" and "b")], $\epsilon_{\mathrm{HH}}(\theta)$ is the $\mathrm{H}-\mathrm{H}$ interaction, and $v_{\circ} \sigma_{i i} / 3$ is the term related to the global expansion or contraction of the lattice upon addition of the second metal $\left(\sigma_{i i}\right.$ is the trace of the corresponding stress tensor, and $v_{\circ}$ is the increment of the lattice volume per $\mathrm{H}$ atom [30]).

We are interested in the effect of addition of $\mathrm{Au}$ to $\mathrm{Pd}$ on $T_{\mathrm{c}}$. From this perspective, the third term [in (1)] is irrelevant and below it is neglected, because it shifts the absorption isotherms but does not influence their phase-transition-related features. The first term is central in our study (Sec. III). The second term can be phenomenologically represented as

$$
\epsilon_{\mathrm{HH}}=-A \theta+\beta A \theta^{3}
$$

where $A$ and $\beta$ are positive constants. The conventional linear attractive part, $-A \theta$, of this interaction results in phase transition. Only with this part are the calculated absorption isotherms symmetric with respect to $\theta=0.5$, while the measured isotherms are highly asymmetric and exhibit a hysteresis loop appreciably shifted to the left. This is related to the repulsive part of the $\mathrm{H}-\mathrm{H}$ interaction, which makes absorption at $\theta \geqslant 0.6$ less favorable. The latter part is sometimes represented by a square term $\left(\propto \theta^{2}\right)$. The cubic term, $\beta A \theta^{3}$, proposed earlier in [31] is, however, more suitable because it increases faster and better suppresses adsorption at $\theta>0.66$.

Despite its simple form (2), the $\mathrm{H}-\mathrm{H}$ interaction is well known to be physically complex (see, e.g., detailed DFT calculations [32]). It includes partly repulsive and partly attractive short-range interactions and attractive long-range interaction. The latter interaction is related to $\mathrm{H}$-induced global elastic expansion of the lattice resulting in the appearance of the tensile stress and reduction of energy [by analogy with the last term in (1)]. In principle, it can be described phenomenologically by using the theory of elasticity (see, e.g., [33]) but the hysteresis loops calculated in the corresponding approximation are not in full agreement with the experiments (see, e.g., the discussion in Sec. 7.3 of Supporting Information in [3]).

The decrease of $T_{\mathrm{c}}$ in a $\mathrm{Pd}-\mathrm{Au}$ alloy can be related to (i) upward shift of the energy of $\mathrm{H}$ atoms in sites containing $\mathrm{Au}$ atoms and (ii) decrease of the $\mathrm{H}-\mathrm{H}$ interaction. At $f \leqslant 0.2$ (this case is of interest), the latter effect is expected to be minor (its scale is $\sim f$ ), and accordingly the DFT part of our work is focused on the former effect. In our subsequent statistical calculations, the $\mathrm{H}-\mathrm{H}$ interaction is considered to be the same as in pure Pd. In particular, we employ $A=0.32 \mathrm{eV}$ and $\beta=0.8$ (with these parameters, the calculated absorption isotherms are properly shifted to the left and exhibit a hysteresis loop with a reasonable width). Our validation of the use of this interaction for an alloy can be classified as a physically reasonable assumption. This assumption appreciably simplifies the requirements for calculations of the absorption isotherms for a Pd-Au alloy. One of the goals of this work was to verify whether the experimental findings can be explained in this framework.

\section{DFT CALCULATIONS}

Our periodic electronic structure DFT calculations were performed in the framework of the spin-unpolarized Vienna Ab initio Simulation Package [34,35] with PerdewBurke-Ernzerhof $[36,37]$ and projector augmented wave pseudopotentials [38,39]. The cutoff energy of plane waves was set to $700 \mathrm{eV}$. Structural optimization was performed until forces acting on each atom were smaller or equal to $0.001 \mathrm{eV} / \AA$. Such high precision was related to the already noticed specifics of the system under consideration, i.e., a large number of possible states and relatively small energy difference (often on the scale of $0.1 \mathrm{eV}$ ) between them.

In pure $\mathrm{Pd}$ and $\mathrm{Pd}-\mathrm{Au}$ alloy, hydrogen can be adsorbed in $\mathrm{O}$ and $\mathrm{T}$ sites. Both the experiments [9] and earlier DFT calculations (reviewed in Sec. I) show that in pure Pd the $\mathrm{O}$ sites are energetically preferable. Our DFT calculations indicate that in a $\mathrm{Pd}-\mathrm{Au}$ alloy these sites remain preferable, and accordingly the emphasis below is on them. The $\mathrm{T}$ sites and their relative role are characterized briefly.

The Au-containing $\mathrm{O}$ sites for hydrogen absorption were modeled by replacing one to five atoms of an $\mathrm{O}$ site in bulk palladium by $\mathrm{Au}$ atoms. To exclude the effect of interaction between periodically repeated $\mathrm{Au}$ atoms, we used the largest possible periodic cell that contained $3 \times 3 \times 3$ elementary fcc cells with a set of $5 \times 5 \times 5 \mathrm{k}$ points. For each arrangement of $\mathrm{Au}$, the sizes of the cell in different directions were optimized. 

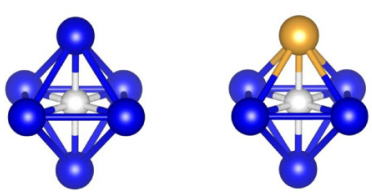

$O\left(P_{6}\right)$

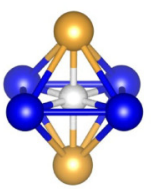

$\mathbf{O}\left(\mathrm{Pd}_{5} \mathrm{Au}_{1}\right)$

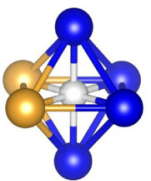

$\mathrm{O}\left(\mathrm{Pd}_{4} \mathrm{Au}_{2}-\mathrm{a}\right)$

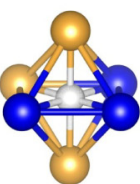

$O\left(\mathrm{Pd}_{3} \mathrm{Au}_{3}-\mathrm{a}\right)$

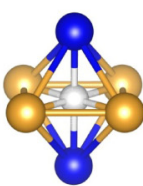

$O\left(\mathrm{Pd}_{2} \mathrm{Au}_{4}-\mathrm{a}\right)$

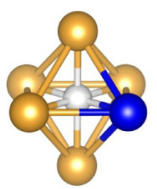

$\mathrm{O}\left(\mathrm{Pd}_{1} \mathrm{Au}_{5}\right)$

$O\left(\mathrm{Pd}_{2} \mathrm{Au}_{4}-\mathrm{b}\right)$

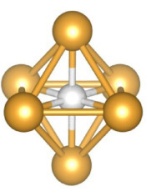

$\mathrm{O}\left(\mathrm{Au}_{6}\right)$

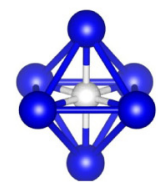

$\mathrm{O}\left(\mathrm{Pd}_{6}\right)$

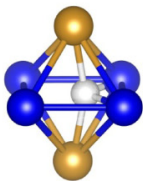

$\mathbf{O}\left(\mathrm{Pd}_{4} \mathrm{Au}_{2}-\mathrm{a}\right)$

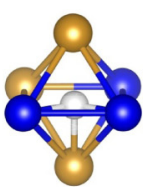

$\mathrm{O}\left(\mathrm{Pd}_{3} \mathrm{Au}_{3}-\mathrm{a}\right)$

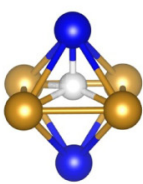

$O\left(\mathrm{Pd}_{2} \mathrm{Au}_{4}-\mathrm{a}\right)$

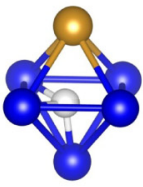

$O\left(\mathrm{Pd}_{5} \mathrm{Au}_{1}\right)$

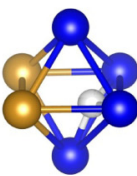

$\mathrm{O}\left(\mathrm{Pd}_{4} \mathrm{Au}_{2}-\mathrm{b}\right)$

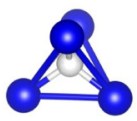

$O\left(\mathrm{Pd}_{3} \mathrm{Au}_{3}-\mathrm{b}\right)$

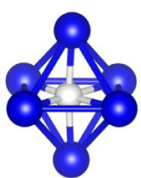

$O\left(\mathrm{Pd}_{2} \mathrm{Au}_{4}-\mathrm{b}\right)$

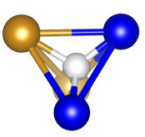

$\mathrm{O}\left(\mathrm{Pd}_{1} \mathrm{Au}_{5}\right)$

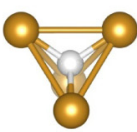

$O\left(A u_{6}\right)$

(a)

(b)

FIG. 1. (a) Unrelaxed and (b) relaxed O sites for hydrogen absorption. In both cases, the designations correspond to the unrelaxed structures. Blue (bright gray) and yellow (dark gray) balls indicate $\mathrm{Pd}$ and $\mathrm{Au}$ atoms. An $\mathrm{H}$ atom is shown by a small white ball in the center of each site.

For this cell, the calculated values of bulk Pd and Au lattice spacings are 3.954 and $4.173 \AA$ (vs 3.89 and $4.08 \AA$ in reality), respectively. Upon hydrogen absorption, the sizes of the cells were, however, fixed, since we realized after several calculations that the changes of the absorption energies related to optimization of cell size after adding the hydrogen were smaller than $0.01 \mathrm{eV}$. The absorption energy was calculated as

$$
E_{\mathrm{abs}}=E(\mathrm{H} \text { in metal })-E(\text { metal })-E\left(\mathrm{H}_{2}\right) / 2,
$$

where $E$ (metal), $E\left(\mathrm{H}\right.$ in metal), and $E\left(\mathrm{H}_{2}\right)$ are the energies of the Pd cell with 0 to 5 atoms replaced by $\mathrm{Au}$, this cell with a $\mathrm{H}$ atom located in it, and a hydrogen molecule in the gas phase, respectively. In the corresponding zero-point energy (ZPE) corrections, only displacements of $\mathrm{H}$ atoms were taken into account, since metal vibrations practically do not affect those of hydrogen.

The $\mathrm{H}$ absorption sites (Fig. 1) are marked as $\mathrm{O}\left(\mathrm{Pd}_{6-n} \mathrm{Au}_{n}\right)$, where $\mathrm{O}$ is associated with "octahedral," and $6-n$ and $n$ are the numbers of $\mathrm{Pd}$ and $\mathrm{Au}$ atoms

surrounding the absorbed hydrogen. For this geometry and $n=2,3$, and 4, there are two different types of arrangements of $\mathrm{Au}$ atoms ("a" and "b" in our designations). Absorption in $\mathrm{T}$ sites of pure $\mathrm{Pd}, \mathrm{T}\left(\mathrm{Pd}_{4}\right)$, and in $\mathrm{O}$ sites of bulk $\mathrm{Au}$, $\mathrm{O}\left(\mathrm{Au}_{6}\right.$-bulk), was also explored. During relaxation (at the level of the whole cell), absorption at some of the sites turned out to be unstable, and the $\mathrm{H}$ atom had left the initial site. For the $\mathrm{O}$ final sites, their designation is the same as for the initial ones, while the $\mathrm{T}$ sites are marked as $\mathrm{T}\left(\mathrm{Pd}_{4-n} \mathrm{Au}_{n}\right)$ with $4-n$ and $n$ corresponding to numbers of $\mathrm{Pd}$ and $\mathrm{Au}$ atoms in the adsorption site.

The calculated energies of the Pd-Au cell without hydrogen, $\mathrm{H}$ absorption energies, and the corresponding frequencies of $\mathrm{H}$ vibrations are presented in Tables I-III, respectively. As expected, the absorption becomes less favorable with increasing $\mathrm{Au}$ content (Table II and Fig. 2). If for given $n$ the type of arrangement of $\mathrm{Au}$ atoms is not unique, the absorption energy is different for different arrangements. For example, the $\mathrm{O}\left(\mathrm{Pd}_{4} \mathrm{Au}_{2}-\mathrm{a}\right)$ and $\mathrm{O}\left(\mathrm{Pd}_{4} \mathrm{Au}_{2}-\mathrm{b}\right)$ sites contain two $\mathrm{Au}$ atoms, and for absorption the latter site is $0.1 \mathrm{eV}$ more favorable. The difference between these sites is in the relative position of $\mathrm{Au}$ atoms. They occupy two opposite corners of the octahedron in case (a) and are neighbors in case (b). The effect of this difference on the energy can be understood by analyzing $\mathrm{H}-\mathrm{Pd}$ and $\mathrm{H}-\mathrm{Au}$ distances in relaxed configurations (Table II). In the relaxed $\mathrm{O}\left(\mathrm{Pd}_{5} \mathrm{Au}_{1}\right)$ structure, the only $\mathrm{H}-\mathrm{Au}$ bond is longer than all H-Pd bonds, so one may say that $\mathrm{Au}$ atoms tend to push hydrogen away, and this is also consistent with the fact that hydrogen absorption is energetically unfavorable in $\mathrm{Au}$. In the sites with more than one $\mathrm{Au}$ atom, such as $\mathrm{O}\left(\mathrm{Pd}_{4} \mathrm{Au}_{2}-\mathrm{a}\right)$, the $\mathrm{H}$-Au distances generally also tend to be longer than H-Pd ones. Some H-Pd bonds are, however, longer than $\mathrm{H}$-Au ones due to geometrical constraints [Fig. 1(b)], and this makes the absorption less favorable. Similar reasoning can be applied to the other absorption sites. So we suppose that the main reason that the $\mathrm{O}\left(\mathrm{Pd}_{4} \mathrm{Au}_{2}-\mathrm{a}\right)$ absorption site is less favorable energetically than the $\mathrm{O}\left(\mathrm{Pd}_{4} \mathrm{Au}_{2}-\mathrm{b}\right)$ site is that in the former the pushing effects of the two $\mathrm{Au}$ atoms are directed against each other while they are more "parallel" in the latter which is less constraining.

In several cases during structural relaxation, the $\mathrm{H}$ atom has left the initial $\mathrm{O}$ site and moved to an adjacent $\mathrm{T}$ site. It happens provided $n \geqslant 3$. This rule is, however, not general: for $\mathrm{O}\left(\mathrm{Pd}_{3} \mathrm{Au}_{3}-\mathrm{a}\right)$ it is not the case, while for $\mathrm{O}\left(\mathrm{Pd}_{3} \mathrm{Au}_{3}-\mathrm{b}\right)$ it is, although $n=3$ in both cases. The same observation can be made for $\mathrm{O}\left(\mathrm{Pd}_{2} \mathrm{Au}_{4}-\mathrm{a}\right)$ and $\mathrm{O}\left(\mathrm{Pd}_{2} \mathrm{Au}_{4}-\mathrm{b}\right)$ sites. Here again this can be explained by the fact that the Au atoms push the $\mathrm{H}$ atom away, and when the $\mathrm{Au}$ atoms are localized close to each other the $\mathrm{H}$ atom is pushed in the direction opposite to them. Indeed in the $\mathrm{O}\left(\mathrm{Pd}_{3} \mathrm{Au}_{3}-\mathrm{b}\right)$ and $\mathrm{O}\left(\mathrm{Pd}_{2} \mathrm{Au}_{4}-\mathrm{b}\right)$ sites, the $\mathrm{Au}$ atoms are located more closely to each other than in $\mathrm{O}\left(\mathrm{Pd}_{3} \mathrm{Au}_{3}\right.$-a) and $\mathrm{O}\left(\mathrm{Pd}_{2} \mathrm{Au}_{4}-\mathrm{a}\right)$, respectively. It is also interesting to notice that in the $\mathrm{O}\left(\mathrm{Pd}_{2} \mathrm{Au}_{4}-\mathrm{b}\right)$ case the $\mathrm{H}$ atom was pushed out into a neighboring $\mathrm{T}\left(\mathrm{Pd}_{3} \mathrm{Au}\right)$ site but did not stay there and was further pushed by the $\mathrm{Au}$ atom of the latter site into an $\mathrm{O}\left(\mathrm{Pd}_{6}\right)$ site.

Our analysis above is limited to the nearest-neighbor $\mathrm{H}-\mathrm{Au}$ interactions. As expected (cf. Sec. I), the corresponding increments of the $\mathrm{H}$ binding energies are relatively small. The next-nearest-neighbor interactions are even smaller and 
TABLE II. Hydrogen absorption energies without $\left(E_{\mathrm{abs}}\right)$ and with $\left(E_{\mathrm{abs}}^{*}\right) \mathrm{ZPE}$ correction and H-Pd and H-Au distances after the lattice relaxation. The initial (before relaxation) and final (after relaxation) absorption sites are given in the first and second columns, respectively. "initial" means that after relaxation the $\mathrm{H}$ atom stayed in its initial site.

\begin{tabular}{|c|c|c|c|c|c|}
\hline Initial site & Final site & $\begin{array}{l}E_{\text {abs }} \\
(\mathrm{eV})\end{array}$ & $\begin{array}{l}E_{\mathrm{abs}}^{*} \\
(\mathrm{eV})\end{array}$ & $\begin{array}{c}d(\mathrm{H}-\mathrm{Pd}) \\
(\AA)\end{array}$ & $\begin{array}{c}d(\mathrm{H}-\mathrm{Au}) \\
(\AA)\end{array}$ \\
\hline $\mathrm{O}\left(\mathrm{Pd}_{6}\right)$ & initial & -0.102 & -0.179 & 2.00 & \\
\hline $\mathrm{O}\left(\mathrm{Pd}_{5} \mathrm{Au}_{1}\right)$ & initial & -0.005 & -0.036 & $\begin{array}{c}1.77,1.89 \\
1.89,2.17 \\
2.17\end{array}$ & 2.34 \\
\hline $\mathrm{O}\left(\mathrm{Pd}_{4} \mathrm{Au}_{2}-\mathrm{a}\right)$ & initial & 0.208 & 0.178 & $\begin{array}{l}1.80,1.80 \\
2.27,2.27\end{array}$ & $2.07,2.07$ \\
\hline $\mathrm{O}\left(\mathrm{Pd}_{4} \mathrm{Au}_{2}-\mathrm{b}\right)$ & initial & 0.044 & 0.072 & $\begin{array}{c}1.74,1.74 \\
1.77,2.49\end{array}$ & $2.53,2.53$ \\
\hline $\mathrm{O}\left(\mathrm{Pd}_{3} \mathrm{Au}_{3}-\mathrm{a}\right)$ & initial & 0.260 & 0.257 & $\begin{array}{c}1.75,1.71 \\
2.41\end{array}$ & $\begin{array}{c}2.10,2.12 \\
2.47\end{array}$ \\
\hline $\mathrm{O}\left(\mathrm{Pd}_{3} \mathrm{Au}_{3}-\mathrm{b}\right)$ & $\mathrm{T}\left(\mathrm{Pd}_{4}\right)$ & -0.115 & -0.070 & $\begin{array}{c}1.79,1.79 \\
1.79,1.80\end{array}$ & \\
\hline $\mathrm{O}\left(\mathrm{Pd}_{2} \mathrm{Au}_{4}-\mathrm{a}\right)$ & initial & 0.522 & 0.462 & 1.712 .36 & $\begin{array}{c}2.08,2.09 \\
2.10\end{array}$ \\
\hline $\mathrm{O}\left(\mathrm{Pd}_{2} \mathrm{Au}_{4}-\mathrm{b}\right)$ & $\mathrm{O}\left(\mathrm{Pd}_{6}\right)$ & -0.139 & -0.215 & $\begin{array}{l}1.96,1.96, \\
2.01,2.01, \\
2.05,2.05\end{array}$ & \\
\hline $\mathrm{O}\left(\mathrm{Pd}_{1} \mathrm{Au}_{5}\right)$ & $\mathrm{T}\left(\mathrm{Pd}_{2} \mathrm{Au}_{2}\right)$ & 0.274 & 0.308 & $1.72,1.72$ & $1.94,1.94$ \\
\hline $\mathrm{T}\left(\mathrm{Pd}_{4}\right)$ & initial & -0.053 & -0.005 & 1.79 & \\
\hline $\mathrm{O}\left(\mathrm{Au}_{6}\right.$-bulk $)$ & $\mathrm{T}\left(\mathrm{Au}_{4}\right.$-bulk $)$ & 0.882 & 0.873 & & 1.91 \\
\hline
\end{tabular}

practically negligible. This is evident, e.g., from the case of an $\mathrm{H}$ atom in the initial $\mathrm{O}\left(\mathrm{Pd}_{2} \mathrm{Au}_{4}-\mathrm{b}\right)$ state where eventually it occupies $\mathrm{O}\left(\mathrm{Pd}_{6}\right)$ and accordingly has four next-nearest-neighbor $\mathrm{Au}$ atoms. The final energy of this atom is fairly close to that in the $\mathrm{O}\left(\mathrm{Pd}_{6}\right)$ state without next-nearest-neighbor $\mathrm{Au}$ atoms (see Table II). The results shown in Fig. 5(a) in [25] are also indicative that the next-nearest-neighbor interactions are small.

Finally, we note that one can try to use the $d$-band model $[40,41]$ in order to interpret some aspects of $\mathrm{H}$ absorption in a Pd-Au alloy. This model is, however, based on the concepts of the phenomenological Newns-Anderson model and the effective medium theory, and its applicability can be debated.

TABLE III. Calculated frequencies of vibrations of $\mathrm{H}$ atoms in the final sites after relaxation. This table complements Table II.

\begin{tabular}{lcc}
\hline \hline Initial site & Final site & $\begin{array}{c}\text { Frequencies } \\
\left(\mathrm{cm}^{-1}\right)\end{array}$ \\
\hline $\mathrm{O}\left(\mathrm{Pd}_{6}\right.$-bulk $)$ & initial & $305,305,305$ \\
$\mathrm{O}\left(\mathrm{Pd}_{5} \mathrm{Au}_{1}\right)$ & initial & $928,408,329$ \\
$\mathrm{O}\left(\mathrm{Pd}_{4} \mathrm{Au}_{2}-\mathrm{a}\right)$ & initial & $703,557,429$ \\
$\mathrm{O}\left(\mathrm{Pd}_{4} \mathrm{Au}_{2}-\mathrm{b}\right)$ & initial & $1159,1038,414$ \\
$\mathrm{O}\left(\mathrm{Pd}_{3} \mathrm{Au}_{3}-\mathrm{a}\right)$ & initial & $1140,738,245$ \\
$\mathrm{O}\left(\mathrm{Pd}_{3} \mathrm{Au}_{3}-\mathrm{b}\right)$ & $\mathrm{T}\left(\mathrm{Pd}_{4}\right)$ & $978,978,944$ \\
$\mathrm{O}\left(\mathrm{Pd}_{2} \mathrm{Au}_{4}-\mathrm{a}\right)$ & initial & $969,111,109$ \\
$\mathrm{O}\left(\mathrm{Pd}_{2} \mathrm{Au}_{4}-\mathrm{b}\right)$ & $\mathrm{O}\left(\mathrm{Pd}_{6}\right)$ & $337,324,283$ \\
$\mathrm{O}\left(\mathrm{Pd}_{1} \mathrm{Au}_{5}\right)$ & $\mathrm{T}\left(\mathrm{Pd}_{2} \mathrm{Au}\right.$ & $1266,880,565$ \\
$\mathrm{~T}\left(\mathrm{Pd}_{4}\right)$ & initial & $676,675,675$ \\
$\mathrm{O}\left(\mathrm{Au}_{6}-\mathrm{bulk}\right)$ & $\mathrm{T}\left(\mathrm{Au}_{4}\right.$-bulk $)$ & $980,980,980$ \\
\hline \hline
\end{tabular}

\section{STRUCTURE OF THE Pd-Au ALLOY}

Metal alloys exhibit various structures [42]. The corresponding studies of a $\mathrm{Pd}-\mathrm{Au}$ alloy can be divided into four groups including experiments with (i) macroscopic bulk samples, (ii) catalytic NPs, (iii) NPs for hydrogen absorption, and (iv) theoretical calculations focused primarily on the energetics.

In area (i), the available data are old, limited, and somewhat contradictory (reviewed in [24]).

In area (ii), the size of NPs is typically 5-20 nm, and the focus is often on the surface and subsurface regions [43]. These regions are expected to be enriched by $\mathrm{Au}$ because the $\mathrm{Au}$ surface energy is lower than that of $\mathrm{Pd}$ [42]. In reality, however, Pd often dominates there presumably due to its stabilization by an adsorbate (e.g., by oxygen) and/or metal-support interaction [43]. The NPs are usually reported to exhibit the core-shell or random-alloy arrangement [43]. After annealing, the latter arrangement becomes preferable [44]. Extended X-ray absorption fine structure (EXAFS) spectroscopy, e.g., confirms this arrangement [45]. The ordered arrangement was reported, e.g., for Au-rich NPs with size $\leqslant 10 \mathrm{~nm}$ at temperatures between 500 and $600{ }^{\circ} \mathrm{C}$ after annealing for a few hours [46]. The ordering occurred in parallel with Ostwald ripening of NPs.

In area (iii), the size of NPs (e.g., nanodisks [5]) is typically larger than in catalysis, and the annealing is performed at relatively high temperatures (at $T \simeq 800 \mathrm{~K}$ for $\sim 24 \mathrm{~h}$ ). The effect of $\mathrm{Au}$ or $\mathrm{Pd}$ segregation at the surface on the hydrogen absorption in such NPs is negligible. Concerning the interior, the corresponding energy-dispersive $\mathrm{x}$-ray (EDX) elemental maps are in favor of the random-alloy arrangement [47]. In principle, the hydrogen absorption can influence the 
arrangement of metal atoms. The experiments are, however, typically performed during short periods of time at relatively low temperatures, so that the diffusion of metal atoms is negligible, and accordingly the absorption does not induce their rearrangement.

DFT-based calculations [area (iv)] are executed with periodic cells [20-22] or at the level of NPs containing $\sim 100$ atoms [23]. A few ordered arrangements were predicted at various values of $f[20]$. The corresponding enthalpies of the formation (per atom) are fairly small, below or comparable to $80 \mathrm{meV}$ (see Fig. 14 in [20] and Fig. 12 in [21]). The corresponding critical temperatures are low as well at all the compositions [24]. In particular, the ordered $L 1_{2}$ state is predicted near $f=0.25$ at $T \leqslant 170 \mathrm{~K}$ and the biphase domain for $f<0.25$ at $T \leqslant 250 \mathrm{~K}$ (Fig. 10 in [24]). At these compositions, the random-alloy approximation is thus acceptable at $T>250 \mathrm{~K}$. This conclusion is supported by Ref. [23] (see also [22]) indicating that the descriptor, $\epsilon_{\mathrm{BOND}}^{\mathrm{Pd}-\mathrm{Au}}$ characterizing the difference of the $\mathrm{Pd}-\mathrm{Pd}, \mathrm{Pd}-\mathrm{Au}$, and $\mathrm{Au}-\mathrm{Au}$ interactions, is fairly small, $\simeq-20 \mathrm{meV}$ (Table 1 in [23]).

Our calculations (Table I) indicate that without hydrogen the difference of the energies of the structures containing different numbers of $\mathrm{Au}$ atoms is determined primarily by the chemical difference of Pd and Au atoms. The difference of the energies of the structures containing the same number of $\mathrm{Au}$ atoms (it can be used to characterize the driving force for the ordering) is found to be fairly low [e.g., $30 \mathrm{meV}$ for $\mathrm{O}\left(\mathrm{Pd}_{4} \mathrm{Au}_{2}-\mathrm{a}\right)$ and $\left.\mathrm{O}\left(\mathrm{Pd}_{4} \mathrm{Au}_{2} \mathrm{~b}\right)\right]$ and cannot result in appreciable correlations in the arrangement of atoms at $f \leqslant 0.2$ and $T \geqslant 300 \mathrm{~K}$

Taken together, the data for a Pd-Au alloy are not fully consistent [24]. In the situation we are interested in (at $f \leqslant$ 0.2 and $T \geqslant 300 \mathrm{~K}$ ), the experiments and theory, however, either support or at least do not contradict the assumption that the atoms in this alloy are distributed at random. A posteriori, this assumption is supported also by our analysis (Sec. V) of the effect of $\mathrm{Au}$ on the isotherms of hydrogen absorption by the Pd-Au NPs.

\section{STATISTICS}

Using the obtained $\mathrm{H}$ binding energies and vibrational frequencies, $\mathrm{H}-\mathrm{H}$ interaction (2), and grand canonical distribution for occupation of sites, we have calculated the absorption isotherms at different $f$ and temperatures. Taking into account that the $\mathrm{T}$ sites are less favorable for hydrogen absorption, the bulk of calculations were performed neglecting these sites. In this case, the absorption is described as

$$
\theta=\sum_{n, i} P_{n, i} p_{n, i}
$$

where $P_{n, i}$ is the probability that an absorption site is in a given state (with $n \leqslant 6$ and given $i$ ), and

$$
p_{n, i}=\frac{F_{n, i} \exp \left[\left\{\mu-\Delta E_{\mathrm{abs}}(n, i)+A \theta-\beta A \theta^{3}\right\} / k_{\mathrm{B}} T\right]}{1+F_{n, i} \exp \left[\left\{\mu-\Delta E_{\mathrm{abs}}(n, i)+A \theta-\beta A \theta^{3}\right\} / k_{\mathrm{B}} T\right]}
$$

is the probability that a site is occupied by $\mathrm{H}\left[\Delta E_{\text {abs }}(n, i)\right.$ is the increment of the absorption energy with respect to that for

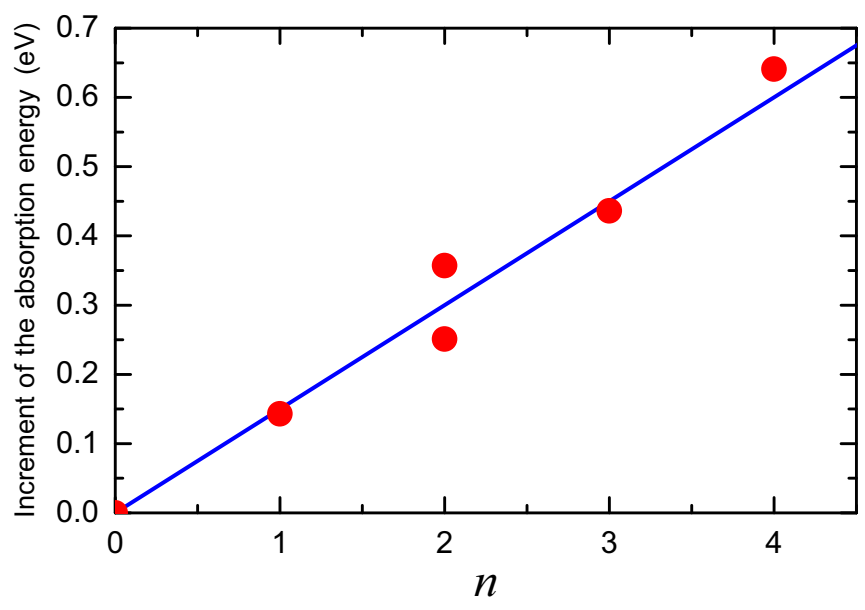

FIG. 2. Increment of the energy (with ZPE correction) of absorption of an $\mathrm{H}$ atom in an $\mathrm{O}$ site as a function of the number of $\mathrm{Au}$ atoms forming a site (according to the data presented in Table II). The general trend in the dependence appears to be linear (straight line) as often used in generic statistical models. Note, however, that the deviations this dependence for $n=2$ and 4 are appreciable. In addition, there is only one data point for two configurations with $n=3$ [because there is no stable state of an $\mathrm{H}$ atom in the other configuration (see Table II)] and there are no data points for $n=5$ and 6 (because there are no stable states in either case). Basically, one of the configurations with $n=3$ and the configurations with $n=5$ and 6 are fully beyond the linear trend.

pure $\mathrm{Pd}, F_{n, i}$ is the partition function for $\mathrm{H}$ vibrations in a site, and $\mu$ is the chemical potential of $\mathrm{H}$ atoms]. At absorptiondesorption equilibrium, $\mu$ and the $\mathrm{H}_{2}$ pressure in the gas phase are related as $\mu=0.5 k_{\mathrm{B}} T \ln \left(P_{\mathrm{H}_{2}}\right)+$ const. Thus, the dependence of $\theta$ on $\mu$ determines an absorption isotherm.

The probabilities $P_{n, i}$ used in (4) depend on the Pd-Pd, $\mathrm{Pd}-\mathrm{Au}$, and $\mathrm{Au}-\mathrm{Au}$ interactions. The differences in these interactions are small, and both the experiment and theory indicate (Sec. IV) that for the conditions of interest $(f \leqslant 0.2$ and $T \geqslant 300 \mathrm{~K}$ ) the distribution of Au atoms is close to random, and accordingly

$$
P_{n}=\frac{m ! f^{n}(1-f)^{m-n}}{n !(m-n) !},
$$

where $m$ is the maximum number of Au atoms in a site $(m=6$ and 4 for $\mathrm{O}$ and T sites, respectively). The probabilities $P_{n, i}$ have been calculated as a product of $P_{n}$ and the probability of having a specific type of a site at given $n$. The latter probability is equal to 1 for $n=0,1,5$, and 6 and to the statistical probabilities of having the "a" and "b" sites for other $n$.

To simplify the comparison of the isotherms calculated in different approximations, we note that the partition function for $\mathrm{H}$ vibrations in the sites formed only by $\mathrm{Pd}$ (i.e., $F_{0,1}$ ) can be included into the chemical potential. With this modification used in the calculations, expression (5) remains the same provided $F_{n, i}$ are redefined as the ratio of the vibrational partition function at given $n$ and $i$ to the vibrational partition function at $n=0$ and $i=1$ (in this case, we obviously have $\left.F_{0,1}=1\right)$. 

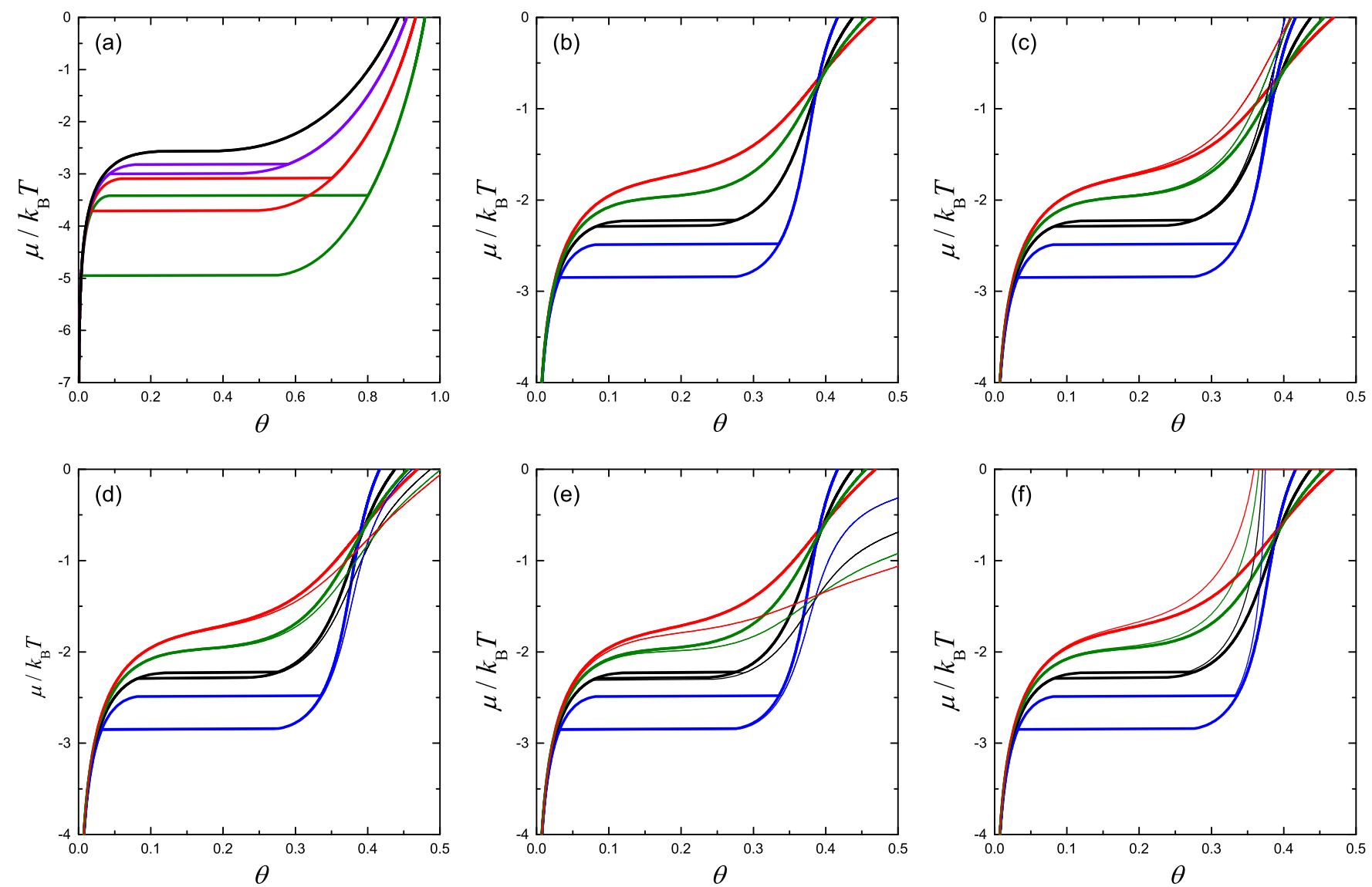

FIG. 3. Hydrogen absorption isotherms calculated in various approximations: (a) for pure Pd at $T=300,400,500$, and $600 \mathrm{~K}$ according to Eq. (7); (b) for a Pd-Au alloy with $f=0.15$ at $T=250,300,350$, and $400 \mathrm{~K}$ (with $T_{\mathrm{c}}=325 \mathrm{~K}$ ) according to Eqs. (4), (6), and (8) with $n \leqslant 2$ and $f_{n, i}=1$; (c) as in (b) but according to Eqs. (4)-(6) with $f_{n, i}$ calculated by using the frequencies from Table I [thin lines; the thick lines presented for comparison are as in (b)]; (d) as in (b) but according to Eqs. (9) and (10) with $n \leqslant 6$ [thin lines; the thick lines presented for comparison are as in (b)]; (e) as in (b) but according to Eq. (11) taking the T sites (with $n=0$ ) into account [thin lines; the thick lines presented for comparison are as in (b)]. Panel (f) is as in (b) but taking only one term with $n=0$ into account. In all the cases [(a)-(f)], the hysteresis loop shrinks with increasing $T$. The parameters for the $\mathrm{H}-\mathrm{H}$ interaction are $A=0.32 \mathrm{eV}$ (or $3700 \mathrm{~K}$ ) and $\beta=0.8$. The absorption energies are from Table II.

For pure Pd, there is only one type of absorption site, and Eqs. (4)-(6) are reduced to

$$
\theta=\frac{\exp \left[\left(\mu+A \theta-\beta A \theta^{3}\right) / k_{\mathrm{B}} T\right]}{1+\exp \left[\left(\mu+A \theta-\beta A \theta^{3}\right) / k_{\mathrm{B}} T\right]} .
$$

The corresponding absorption isotherms are shown in Fig. 3(a).

If the vibrational partition functions are neglected (i.e., $F_{n, i}=1$ ), Eq. (5) reads as

$$
p_{n, i}=\frac{\exp \left[\left\{\mu-\Delta E_{\mathrm{abs}}(n, i)+A \theta-\beta A \theta^{3}\right\} / k_{\mathrm{B}} T\right]}{1+\exp \left[\left\{\mu-\Delta E_{\mathrm{abs}}(n, i)+A \theta-\beta A \theta^{3}\right\} / k_{\mathrm{B}} T\right]} .
$$

The absorption isotherms calculated by using Eqs. (4), (6), and (8) and taking into account only the configurations with $n \leqslant 2$ are shown in Fig. 3(b). The comparison of these absorption isotherms with those obtained by employing Eqs. (4)-(6) and taking into account the vibrational partition functions calculated with the frequencies given in Table III is exhibited in Fig. 3(c). One can see that the isotherms in general and especially the hysteresis loops are nearly identical.
To illustrate the role of the configurations with $n>2$, we neglect the dependence of the $\mathrm{H}$ absorption energy on $i$ and use $\Delta E_{\mathrm{abs}}(n, i)=\epsilon_{\mathrm{HAu}} n$, where $\epsilon_{\mathrm{HAu}}$ is the average increment of the absorption energy per Au atom (as shown by the straight line in Fig. 2). In this case, Eqs. (4) and (8) are reduced to

$$
\begin{gathered}
\theta=\sum_{n} P_{n} p_{n}, \\
p_{n}=\frac{\exp \left[\left(\mu-\epsilon_{\mathrm{HAu}} n+A \theta-\beta A \theta^{3}\right) / k_{\mathrm{B}} T\right]}{1+\exp \left[\left(\mu-\epsilon_{\mathrm{HAu}} n+A \theta-\beta A \theta^{3}\right) / k_{\mathrm{B}} T\right]} .
\end{gathered}
$$

The corresponding absorption isotherms [Fig. 3(d)] show that accounting for the configurations with $n>2$ changes slightly the absorption isotherms at relatively high pressures where the uptake is appreciable. The hysteresis loops are, however, nearly identical to those exhibited in Fig. 3(b).

In general, the absorption isotherms are influenced by the presence of $\mathrm{T}$ sites. These sites can be taken into account by extending Eq. (4) as

$$
\theta=\sum_{n, i} P_{n, i} p_{n, i}+\sum_{n, i} 2 P_{n, i}^{*} p_{n, i}^{*},
$$




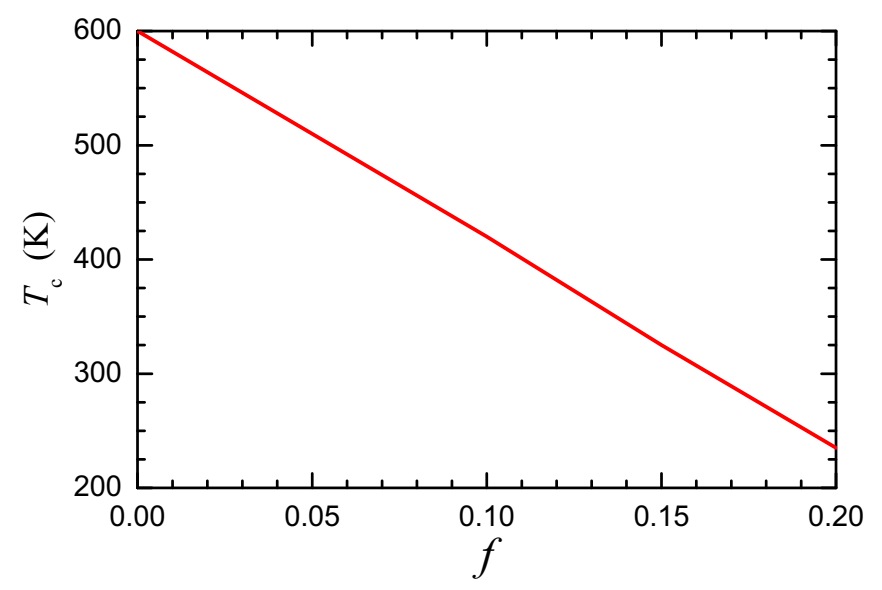

FIG. 4. Critical temperature for hydride formation as a function of the fraction of $\mathrm{Au}$ atoms in a Pd-Au alloy. The curve shown was constructed by using a large array of absorption isotherms like those exhibited in Fig. 2(b).

where the first term corresponds to O sites [as in (4)], while the second term describes the contribution of T sites. In this equation, $\theta$ is the average number of $\mathrm{H}$ atoms per $\mathrm{O}$ site $(\theta$ is calculated taking all hydrogen atoms into account irrespective of the type of absorption sites). The probabilities $p_{n, i}^{*}$ and $P_{n, i}^{*}$ for T sites are defined by analogy with (5) and (6). The numerical coefficient, 2 , takes into account that the number of $\mathrm{T}$ sites is two times larger compared to that of octahedral sites. The absorption in T sites with $n=0$ is energetically unfavorable compared to that in octahedral sites with $n=0$. The absorption in T sites with $n \geqslant 1$ is even more unfavorable and accordingly can be neglected. The absorption isotherms [Fig. 3(e)] calculated by using this approximation and neglecting the vibrational partition functions show that although accounting for the $T$ sites change slightly the absorption isotherms at relatively high pressures, the hysteresis loops remain nearly identical to those exhibited in Fig. 3(b).

Finally, it is instructive to show the absorption isotherms calculated employing Eqs. (4), (6), and (8) and taking into account only one configuration with $n=0$ [Fig. 3(f)]. It is of interest that in principle this simplest approximation is sufficient in order to illustrate the drop of $T_{\mathrm{c}}$ with increasing Au content.

Taken together, the results of our calculations [Figs. 3(b)3(e)] indicate that the effect of $\mathrm{Au}$ on $T_{\mathrm{c}}$ can be reliably illustrated by using the absorption isotherms calculated taking into account only configurations with $n \leqslant 2$ and neglecting the vibrational partition functions and $\mathrm{T}$ sites.
In the absorption isotherms, $T_{\mathrm{c}}$ is associated with the appearance of a hysteresis loop. To obtain $T_{\mathrm{c}}$, it is sufficient, as explained above, to use the isotherms calculated taking into account only hydrogen adsorption at the $\mathrm{O}$ sites with $n \leqslant 2$ and neglecting the vibrational partition functions (i.e., setting $F_{n, i}=1$ ). Such isotherms [e.g., Fig. 3(b)] exhibit the features already described in the beginning of the article and indicate that $T_{\mathrm{c}}$ rapidly decreases with increasing $f$ and becomes lower than room temperature already at $f \simeq 0.15-0.2$ (see Fig. 4, and note that we are interested in the region with $T \geqslant 300 \mathrm{~K}$ ), in good agreement with the available experiments $[4,6,7]$. The agreement was reached without any specially introduced fitting parameters. The only extra parameters, $A$ and $\beta$, used in our calculations were obtained from the measured isotherms of adsorption in Pd.

The key factor behind decreasing $T_{\mathrm{c}}$ with increasing $f$ is that in the system under consideration the phase transition is related primarily to absorption in sites formed only by Pd. With increasing $f$, the fraction of such sites rapidly decreases, the distance between $\mathrm{H}$ atoms located at such sites becomes on average larger, the interaction between them becomes weaker, and accordingly the driving force for the phase transition decreases. In other words, the decrease of $T_{\mathrm{c}}$ with increasing $f$ is related to increasing heterogeneity of the absorption sites.

\section{CONCLUSION}

In summary, our study shows that DFT is efficient for studies of various aspects of hydrogen absorption in a Pd-Au alloy. With the DFT input, we have reproduced special features of the hydrogen absorption isotherms and explained rapid decrease of the corresponding critical temperature with increasing $\mathrm{Au}$ fraction.

Finally, we notice that now the experimental studies of hydrogen absorption in various alloys are numerous (see, e.g., the references in $[2,8]$ ). As a rule, such studies are fully empirical and oriented to applications. Our work indicates that DFT can be efficiently used in the these cases as well.

\section{ACKNOWLEDGMENTS}

This work was supported by the Federal Agency for Scientific Organizations (project 0303-2016-0001). M.M. is grateful to the Siberian Supercomputer Center of the Siberian Branch of the Russian Academy of Sciences and the Supercomputer Center at Moscow State University [48] for providing the computing resources. V.P.Zh. thanks B. Kasemo, I. Zorić, H. Grönbeck, C. Langhammer, S. Alekseeva (Syrenova), F.A.A. Nugroho, and C. Wadell for useful discussions.
[1] R. Kirchheim and A. Pundt, Hydrogen in metals, in Physical Metallurgy, edited by D. E. Laughlin and K. Hono (Elsevier, Amsterdam, 2014), pp. 2597-2705.

[2] A. Schneemann et al., Nanostructured metal hydrides for hydrogen storage, Chem. Rev. 118, 10775 (2018).
[3] S. Syrenova et al., Hydride formation thermodynamics and hysteresis in individual Pd nanocrystals with different size and shape, Nat. Mater. 14, 1236 (2015).

[4] F. A. A. Nugroho et al., Metalpolymer hybrid nanomaterials for plasmonic ultrafast hydrogen detection, Nat. Mater. 18, 489 (2019). 
[5] F. A. A. Nugroho, I. Darmadi, V. P. Zhdanov, and C. Langhammer, Universal scaling and design rules of hydrogeninduced optical properties in Pd and Pd-Alloy Nanoparticles, ACS Nano 12, 9903 (2018).

[6] S. Luo, D. Wang, and T. B. Flanagan, Thermodynamics of hydrogen in fcc Pd-Au alloys, J. Phys. Chem. B 114, 6117 (2010).

[7] C. Wadell et al., Hysteresis-free nanoplasmonic Pd-Au alloy hydrogen sensors, Nano Lett. 15, 3563 (2015).

[8] V. P. Zhdanov, A generic statistical model of hydride formation in a random alloy, Mod. Phys. Lett. B 30, 1650330 (2016).

[9] L. Cser et al., Neutron holographic study of palladium hydride, Appl. Phys. Lett. 85, 1149 (2004).

[10] R. Caputo and A. Alavi, Where do the $\mathrm{H}$ atoms reside in $\mathrm{PdH}_{x}$ systems? Mol. Phys. 101, 1781 (2003).

[11] H. Grönbeck and V. P. Zhdanov, Effect of lattice strain on hydrogen diffusion in Pd: A density functional theory study, Phys. Rev. B 84, 052301 (2011).

[12] A. Houari, S. F. Matar, and V. Eyert, Electronic structure and crystal phase stability of palladium hydrides, J. Appl. Phys. 116, 173706 (2014).

[13] K. Lee, M. Yuan, and J. Wilcox, Understanding deviations in hydrogen solubility predictions in transition metals through first-principles calculations, J. Phys. Chem. C 119, 19642 (2015).

[14] L. E. Isaeva, D. I. Bazhanov, E. I. Isaev, S. V. Eremeev, S. E. Kulkova, and I. A. Abrikosov, Dynamic stability of palladium hydride: An ab initio study, Int. J. Hydrogen Energy 36, 1254 (2011).

[15] M. P. Belova, A. B. Syzdykova, Yu. Kh. Vekilova, and I. A. Abrikosov, Hydrogen in palladium: Anharmonicity of lattice dynamics from first principles, Phys. Solid State 57, 260 (2015).

[16] H. Kimizuka, S. Ogata, and M. Shiga, Mechanism of fast lattice diffusion of hydrogen in palladium: Interplay of quantum fluctuations and lattice strain, Phys. Rev. B 97, 014102 (2018).

[17] Y. Nanba, T. Tsutsumi, T. Ishimoto, and M. Koyama, Theoretical study of the hydrogen absorption mechanism into a palladium nanocube coated with a metal-organic framework, J. Phys. Chem. C 121, 14611 (2017).

[18] K. Namba et al., Acceleration of hydrogen absorption by palladium through surface alloying with gold, Proc. Natl. Acad. Sci. USA 115, 7896 (2018).

[19] R. Nazarov, T. Hickel, and J. Neugebauer, Ab initio study of H-vacancy interactions in fcc metals: Implications for the formation of superabundant vacancies, Phys. Rev. B 89, 144108 (2014).

[20] S. V. Barabash, V. Blum, S. Müller, and A. Zunger, Prediction of unusual stable ordered structures of Au-Pd alloys via first-principles cluster expansion, Phys. Rev. B 74, 035108 (2006).

[21] M. H. F. Sluiter, C. Colinet, and A. Pasturel, Ab initio calculation of the phase stability in Au-Pd and Ag-Pt alloys, Phys. Rev. B 73, 174204 (2006).

[22] B. Zhu, J. Creuze, C. Mottet, B. Legrand, and H. Guesmi, CO adsorption-induced surface segregation and sormation of $\mathrm{Pd}$ chains on AuPd(100) alloy: Density functional theory based Ising model and Monte Carlo simulations, J. Phys. Chem. C 120, 350 (2016).
[23] G Kovács, S. M. Kozlov, and K. M. Neyman, Versatile optimization of chemical ordering in bimetallic nanoparticles, J. Phys. Chem. C 121, 10803 (2017).

[24] F. Berthier, J. Creuze, T. Gabard, B. Legrand, M.-C. Marinica, and C. Mottet, Order-disorder or phase-separation transition: Analysis of the Au-Pd system by the effective site energy model, Phys. Rev. B 99, 014108 (2019).

[25] C. G. Sonwane, J. Wilcox, and Y. H. Ma, Solubility of hydrogen in PdAg and PdAu binary alloys using density functional theory, J. Phys. Chem. B 110, 24549 (2006).

[26] S. Xu, P. Sood, M. L. Liu, and A. Bongiorno, First-principles study of hydrogen permeation in palladium-gold alloys, Appl. Phys. Lett. 99, 181901 (2011).

[27] N. J. J. Johnson et al., Facets and vertices regulate hydrogen uptake and release in palladium nanocrystals, Nat. Mater. 18, 454 (2019).

[28] M. Yamauchi, R. Ikeda, H. Kitagawa, and M. Takata, Nanosize effects on hydrogen storage in palladium, J. Phys. Chem. C 112, 3294 (2008).

[29] V. P. Zhdanov and B. Kasemo, The formation of a new phase in nanoparticles, Physica E 41, 775 (2009).

[30] F. C. Larche, The role of stresses on phase transitions, in Advances in Phase Transitions, edited by J. D. Embury and G. R. Purdy (Pergamon, Oxford, 1988), pp. 193-203.

[31] A. Mällo, FEM calculations of the elastic H-H interaction energy for hydrogen in metals, J. Less-Common Met. 168, 361 (1991).

[32] Y. Wang, S. N. Sun, and M. Y. Chou, Total-energy study of hydrogen ordering in $\mathrm{PdH}_{x}(0 \leqslant x \leqslant 1)$, Phys. Rev. B 53, 1 (1996).

[33] R. B. Schwarz and A. G. Khachaturyan, Thermodynamics of open two-phase systems with coherent interfaces: Application to metal-hydrogen systems, Acta Mater. 54, 313 (2006).

[34] G. Kresse and J. Hafner, Ab initio molecular-dynamics simulation of the liquid-metal-amorphous-semiconductor transition in germanium, Phys. Rev. B 49, 14251 (1994).

[35] G. Kresse and J. Furthmüller, Efficient iterative schemes for ab initio total-energy calculations using a plane-wave basis set, Phys. Rev. B 54, 11169 (1996).

[36] J. P. Perdew, K. Burke, and M. Ernzerhof, Generalized Gradient Approximation Made Simple, Phys. Rev. Lett. 77, 3865 (1996).

[37] J. P. Perdew, K. Burke, and M. Ernzerhof, Erratum: Generalized Gradient Approximation Made Simple [Phys. Rev. Lett. 77, 3865 (1996)], Phys. Rev. Lett. 78, 1396(E) (1997).

[38] P. E. Blöchl, Projector augmented-wave method, Phys. Rev. B 50, 17953 (1994).

[39] G. Kresse and D. Joubert, From ultrasoft pseudopotentials to the projector augmented-wave method, Phys. Rev. B 59, 1758 (1999).

[40] B. Hammer and J. K. Nørskov, Electronic factors determining the reactivity of metal surfaces, Surf. Sci. 343, 211 (1995).

[41] B. Hammer and J. K. Nørskov, Why gold is the noblest of all the metals, Nature (London) 376, 238 (1995).

[42] R. Ferrando, J. Jellinek, and R. L. Johnston, Nanoalloys: From theory to applications of alloy clusters and nanoparticles, Chem. Rev. 108, 845 (2008).

[43] P. Paalanen, B. M. Weckhuysen, and M. Sankar, Progress in controlling the size, composition and nanostructure of supported gold-palladium nanoparticles for catalytic applications, Catal. Sci. Technol. 3, 2869 (2013). 
[44] Z. Wu et al., Surface faceting and compositional evolution of Pd@Au core-shell nanocrystals during in situ annealing, Phys. Chem. Chem. Phys. 21, 3134 (2019).

[45] J. Timoshenko et al., Probing atomic distributions in mono- and bimetallic nanoparticles by supervised machine learning, Nano Lett. 19, 520 (2019).

[46] J. Nelayah, N. T. Nguyen, D. Alloyeau, G. Y. Wang, and C. Ricolleau, Long-range chemical orders in Au-Pd nanoparticles revealed by aberration-corrected electron microscopy, Nanoscale 6, 10423 (2014).
[47] F. A. A. Nugroho, B. Iandolo, J. B. Wagner, and C. Langhammer, Bottom-up nanofabrication of supported noble metal alloy nanoparticle arrays for plasmonics, ACS Nano 10, 2871 (2016).

[48] V. Sadovnichy, A. Tikhonravov, V. Voevodin, and V. Opanasenko, "Lomonosov": Supercomputing at Moscow State University, in Contemporary High Performance Computing: From Petascale toward Exascale, edited by J. S. Vetter (Chapman and Hall/CRC, Boca Raton, 2013), pp. 283-307. 